Revista Herencia, Vol. 33 (1), enero-junio, 2020.

\title{
BOLETOS DE CAFÉ Y FICHAS DE EMPRESAS: HERENCIAS COLECCIONABLES
}

\author{
Coffee tokens and trade tokens: historical inheritance
}

\author{
José A. Vargas Zamora \\ Universidad de Costa Rica, Costa Rica \\ jose.vargas@ucr.ac.cr
}

Recibido: 18-10-2019

Aprobado: 29-11-2019

\begin{abstract}
José A. Vargas Zamora es Profesor Emérito de Escuela de Biología de la Universidad de Costa Rica. Ph.D. en Oceanografía y especialista en ecología de los fondos marinos. Ha escrito sobre las monedas, medallas, billetes, boletos de café y otros objetos numismáticos.
\end{abstract}

\section{RESUMEN}

En Costa Rica, a mediados del siglo XIX hubo un incremento significativo de nuevas plantaciones de café. La necesidad de pagar a los trabajadores, junto con la escasez de moneda de plata de baja denominación, forzó la introducción de una forma privada de pago temporal, los boletos de café, que eran entregados a los trabajadores por cada unidad de café recolectado y luego eran cambiados por dinero usualmente al final de la semana. A fines del siglo XIX la apertura del ferrocarril a la costa Caribe y el desarrollo de plantaciones de banano a lo largo de la vía férrea, promovió la introducción de otra forma de pago privada, las fichas de comisariato, que eran cambiables por abarrotes o utensilios en locales comerciales a lo largo de la vía férrea. En este trabajo analizamos las diferencias y usos de esas dos formas de pago, aportamos ejemplos de ambas y hacemos sugerencias para el estudio y preservación de esta herencia histórica.

Palabras clave: Costa Rica; café; moneda privada; boletos; fichas; banano; herencia

\section{ABSTRACT}

In Costa Rica during the mid XIX century there was a significant increase in the number of new coffee plantations. The need to pay the workers, together with the scarcity of low denomination silver coinage, forced the introduction of a temporay private form of payment, coffee tokens, that were given to the workers for each unit of coffee harvested and were exchanged for money usually at the end of the week. At the end of the XIX century the opening of the railroad tracks to the Caribbean coast and the development of banana plantations along its sides promoted the introduction of another form of private temporary payment, trade tokens, which were exchangeable for groceries or utensils at commercial posts along the tracks. In this work we analize the differences and uses of these two forms of payment, include examples of both, and make suggestions for the study and preservation of this historical inheritance.

Keywords: Costa Rica; coffee; private money; tokens; banana; inheritance 


\section{Introducción}

La economía de Costa Rica a través de su historia ha estado fundamentada en el cultivo de varias especies vegetales, algunas originarias del continente, como el cacao (Theobroma cacao) y el tabaco (Nicotiana tabacum) y otras introducidos al Nuevo Mundo, como el café (Coffea arabica) y el banano (Musa acuminata). Las semillas de cacao, además de ser el ingrediente principal para la bebida de chocolate, sirvieron de moneda durante la época colonial e inicios de siglo XIX debido a la escasez de circulante. Las semillas fueron legalizadas para su uso como moneda en 1709 por don Lorenzo de Granda y Balbín, quien fue gobernador de Costa Rica entre 1707 y 1712 (Chacón-Hidalgo, 2008). Según nos relata González-Zeledón (1947: p. 127), en los albores del siglo XIX el cacao en grano se negociaba a ocho manos por un real (40 semillas por una moneda de plata de un real).

El establecimiento de plantaciones de café (cafetales) desde principios del siglo XIX y su cultivo posterior a gran escala durante más de siglo y medio provocó, a mediados de ese siglo, un cambio radical en la economía del país y en el modo de vida de los costarricenses (Vega-Jiménez, 1991). Sin embargo, el auge del café no corrió paralelo con la disponibilidad de la moneda de plata de baja denominación (reales) necesaria para pagar a los peones y a los recolectores del grano. Esto favoreció, por ahí de 1840, la emisión privada de una forma de pago transitoria conocida como boleto de café, fabricada en bronce y luego en otros metales. La escasez de moneda fue parcialmente solucionada a mediados del siglo XIX con la introducción de monedas extranjeras y su habilitación mediante resellos. Además, entraron en circulación monedas de plata y de oro emitidas por la Casa de Moneda a partir de 1829. No obstante, la conveniencia del uso de boletos se mantiene hasta hoy, por otras razones.

La exportación de café, realizada principalmente entre 1845 y 1886 directamente a Europa desde el puerto de Puntarenas vía Cabo de Hornos, por los veleros de la compañía fundada por el capitán inglés William Le Lacheur, se tornó lenta y poco rentable por la conclusión, en 1890, del ferrocarril al Caribe (León-Sáenz, 1997, p. 271). El ferrocarril facilitó el envío de café a mercados norteamericanos y europeos a través del puerto de Limón. El tren también abrió el camino a un nuevo cultivo, el banano, y a la introducción a lo largo de la vía, especialmente entre Turrialba y Limón, de otra forma de pago privada (las fichas de comisariato), por los administradores que controlaban el empleo en el 
ferrocarril y en las plantaciones del nuevo cultivo. Las fichas eran emitidas por los administradores, o por empresarios asociados que ejercían gran parte del comercio en establecimientos (comisariatos), donde los obreros se veían obligados a cambiar las fichas por alimentos y otros insumos.

El uso de los boletos de café sobrevive en la actualidad. Si bien las fichas de comisariato desaparecieron, el uso de fichas en otros tipos de actividades comerciales se mantuvo durante gran parte del siglo XX y hoy sobreviven algunas; por ejemplo, en locales de juegos de azar.

En este escrito aportamos algunos datos sobre el uso de estas formas de pago provisionales e incluimos ejemplos seleccionados de varias piezas, cuya existencia ha sido preservada en gran parte por su valor para el interesado en la ciencia numismática en particular y para el coleccionista de objetos antiguos en general.

\section{El auge del cultivo del café}

El café es originario de Etiopía y fue llevado al Nuevo Mundo por los europeos, quienes en el siglo XVIII lo plantaron en algunas islas del Caribe. Según González-Flores, 1934, p. 477) hay al menos dos versiones sobre quién fue el responsable de su importación en Costa Rica: la primera indica que las semillas fueron traídas por el comerciante don Agustín de Gana por encargo de don José Vázquez y Téllez, quien ejerció el cargo de gobernador de Costa Rica entre 1789 y 1796. La otra versión propone su introducción a fines del siglo XVIII, o principios del siglo XIX, por don Tomás de Acosta, quien fue gobernador entre 1796 y 1810. Lo cierto es que correspondió a don Tomás el promover el cultivo del fruto en Cartago y luego en San José. El 18 de junio de 1804 este gobernador publicó un bando declarando libres de pagar derechos las nuevas plantaciones de algodón, añil, cacao, café, y la extracción de azúcar (Fernández, 1889, p. 452). En 1816 en el testamento del sacerdote Félix Velarde se indicó que la producción de su cafetal, estimada en 11 fanegas en un solar o cuarto de manzana ubicado en el centro de San José, fue valorada en 55 pesos (GonzálezFlores, 1934, p. 482). Ese precio, novedoso para la época, posiblemente despertó el interés en el cultivo a mayor escala y es un indicador de que ya se estaba extendiendo el gusto por esa bebida en una población acostumbrada a beber chocolate en jícara en las reuniones sociales o de negocios. 
La siembra de grandes plantaciones de café en las primeras décadas del siglo XIX nos lleva a preguntarnos de dónde provino gran parte del capital para la compra de tierras, la preparación de los terrenos, la siembra de los cafetos y el pago de los cosechadores. Un hecho histórico es relevante en este contexto: En el año 1815 el obispo don Nicolás García, en su visita apostólica a Costa Rica, hizo la observación de que las laderas del camino en los Montes del Aguacate parecían contener oro. Uno de los encargados de recibir al prelado, don Santos Lombardo, tomó muestras de las tierras y al analizarlas en Cartago confirmó la observación del obispo. Don Santos, junto con don José Rafael de Gallegos, quien años después sería Jefe de Estado, denunciaron la mina Sacra Familia (Mellis, 1891, p. 3). La presencia del metal desató una fiebre de oro y una oleada de mineros y de denunciantes de nuevas minas. Araya-Pochet (1973) aporta una lista de los segundos, quienes entre 1821 y 1831 hicieron 176 denuncios. Entre los nombres se reconocen muchos de los que luego serían grandes productores de café y tendrían influencia directa en la política (la oligarquía cafetalera) de Costa Rica. Muchos de ellos se convirtieron en productores y procesadores (beneficiadores) del grano, en exportadores, o en beneficiadores-exportadores. Sus capitales les permitían también financiar las cosechas de productores menores quienes debían asociarse a los primeros para poder vender su producto. En muchos casos las frecuentes caídas del precio del café les hacían perder sus pequeñas plantaciones a favor de los grandes propietarios que, de este modo, incrementaban su patrimonio. Según lo indica Gudmundson (1993, p. 194):

\begin{abstract}
El café transformó fundamentalmente un régimen colonial y una economía aldeana que se basaba en la extracción directa por parte de una clase dominante urbana de un campesinado, aun poco privatizado. El reemplazo de esa extracción directa por mecanismos más sutiles y productivos de mercado creo una relación antagónica, cualitativamente nueva, entre la élite cafetalera de exportadores y beneficiadores y un campesinado terrateniente crecientemente mercantil...
\end{abstract}

\title{
La falta de circulante y los resellos de monedas extranjeras
}

El auge del cultivo del café y la llegada anual de las cosechas hizo necesario el buscar alternativas que facilitaran el pago a los peones (jornaleros) y a los cosechadores (cogedores). El principal problema durante la primera mitad del siglo XIX fue la escasez de moneda de plata de baja denominación (1/2 real, 1 real, 2 reales). Si bien desde 1829 la Casa de Moneda puso en circulación moneda de oro (escudos), su valor relativamente alto ( 1 Escudo $=16$ reales) no 
hacía práctico su uso en el pago de los trabajadores. Por ejemplo, el viajero escocés Robert Dunlop, quien estuvo en Costa Rica en 1844 y visitó varias plantaciones de café, menciona que la mano de obra en ellas se pagaba a dos reales el día (Fernández-Guardia, 2002: p. 90). Entre 1831 y 1849 la Casa de Moneda hizo varias acuñaciones de reales, medios reales y, en 1845, la única emisión de cuartos de real o cuartillos (Murillo, 2004, p. 44) No obstante, la demanda de moneda aumentaba y una de las formas de mitigar en parte esa escasez fue la introducción de moneda extranjera, cuyo contenido de plata fuese similar al aceptado en Costa Rica. Las monedas aceptadas fueron habilitadas para circular en Costa Rica mediante la aplicación de resellos por la Casa de Moneda.

En 1841 el Jefe de Estado don Braulio Carrillo decretó el resellado de monedas de plata de $8,4,2,1$, y 1/2 real provenientes de varios países, especialmente de Bolivia, Guatemala, México y Perú (Murillo, 2004: p. 49). En 1845, don José Rafael de Gallegos emitió el decreto para el resellado de pesetas españolas como equivalentes a dos reales (Vargas Zamora, Chacón-Hidalgo \& SánchezChaves, 2018). En 1846, por decreto de don José María Alfaro se procedió a resellar las monedas macuquinas de 8, 4, 2, y 1 real. La moneda colonial macuquina, además de escasa presentaba otros problemas, pues existían muchas falsas y su forma irregular facilitaba la sustracción de pequeños fragmentos de plata (Murillo, 2004, p. 56). En 1850, durante el gobierno del presidente de la República, don Juan Rafael Mora, fueron reselladas monedas inglesas de seis peniques (six pence) y de un chelín (shilling), para habilitar su circulación como piezas de un real y de dos reales, respectivamente (Murillo, 2004, p. 81). Don Juan Rafael y su hermano don José Joaquín fueron cafetaleros importantes a mediados del siglo XIX. Gran parte de esas monedas inglesas fueron introducidas por los veleros de William Le Lacheur como pago por café transportado y vendido en Europa. Por ejemplo, el 2 de abril de 1845 su nave Monarch ingresa a Puntarenas con 36.700 pesos ( 1 Peso $=8$ reales) en dinero y el 9 de mayo zarpa de regreso a Inglaterra con 5599 quintales de café (Vargas Zamora, Chacón-Hidalgo \& SánchezChaves, 2018, p. 11). En la Figura 1 incluimos ejemplos de los tipos de monedas reselladas. 
Figura 1. Resello de 1841 (estrella radiante de 6 puntas y agujero) sobre moneda de 2 reales, Perú, 1828. B. Doble resello de 1845 (Busto de mujer / árbol de ceiba) sobre moneda de 2 reales (peseta), Madrid, 1800. C. Doble resello de 1846 (Tres volcanes y sol / árbol de ceiba) sobre moneda macuquina de 2 reales, Potosí ?, 1718. D. Resello de 1850 (León pasante), sobre monedas inglesas de Six Pence (1835) y One Shilling (1844), habilitadas para circular por uno y dos reales, respectivamente.

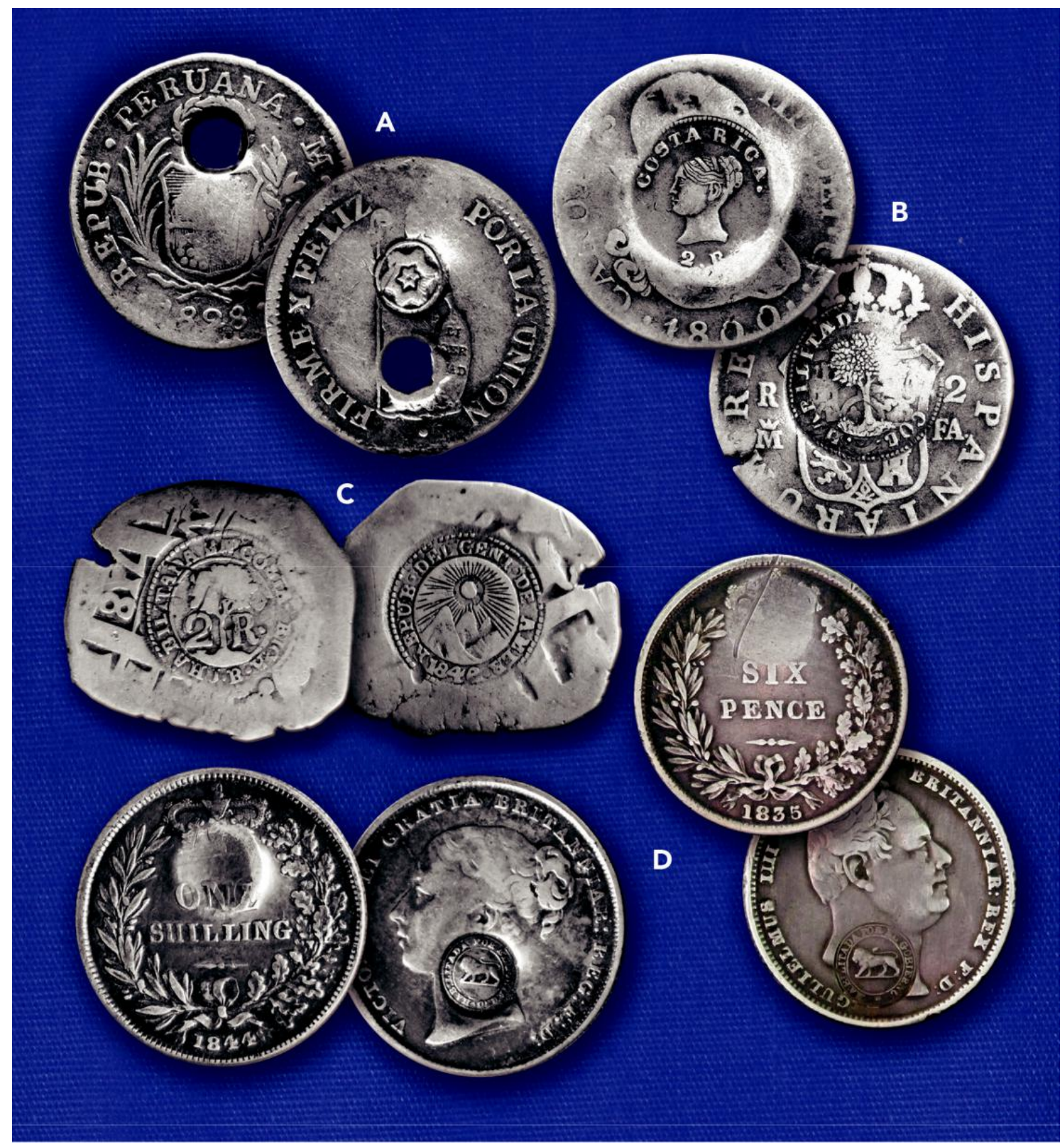

Fuente: Fotos A-D José A. Vargas Zamora. Colecciones privadas, 2019 
Figura 2. Ejemplos de boletos de café emitidos desde mediados del siglo XIX hasta mediados del XX. A. Juan R. Mora (JRM). Medio real. Finca Francfort. San José. B. Henry Guier Stone, Medio real. Cartago. C. Doble contramarca Francisco Pinto (ver Murillo, 2004: 134), 1864, sobre un centavo de E.E.U.U. D. Diez centavos, 1879, Ceferino Fernández. Santa Elena. Cartago. E. Veinticinco centavos, 1894, Antolín Chinchilla. Alajuela F. Cinco céntimos, José A. Peña. Turrialba. G. Contramarca G A (Gaspar Arias), 2 (cajuelas), sobre moneda de 25 céntimos de 1924 en desuso. Heredia. H. Un canasto, Francisco Montealegre. Mediados del siglo XIX. San José. I. Media medida, La Marta. Otto Fernández. Cartago. J. Dos (II) cajuelas. Juan Hernández. El Patalillo. San José. K. Vale por 10 boletos. Carlos M. Sánchez. Heredia. L. Boleto artesanal. Diez medidas (10 M), Juvenal Villalobos. Heredia. M. Una cajuela. Prof. José A. Vargas, sobre machote de Almacén Gamboa. 1962. Heredia. N. Boleto de cartón. Una medida. Augusto Durán. Heredia. O. Boleto plástico. Rogelio Rojas Troyo, una cajuela. Hacienda La Esperanza, Cartago. P. Contramarca C. Z. (Cornelia Zamora), sobre ficha (Token: 3 / To Hannover) europea. Heredia. Q. Boleto para pago de escogida (descogida) de café. Hacienda de País. José P. Rojas. R. Boleto para pago de escogida de café. Una medida (I). San Rafael. Teodosio Castro. San José.

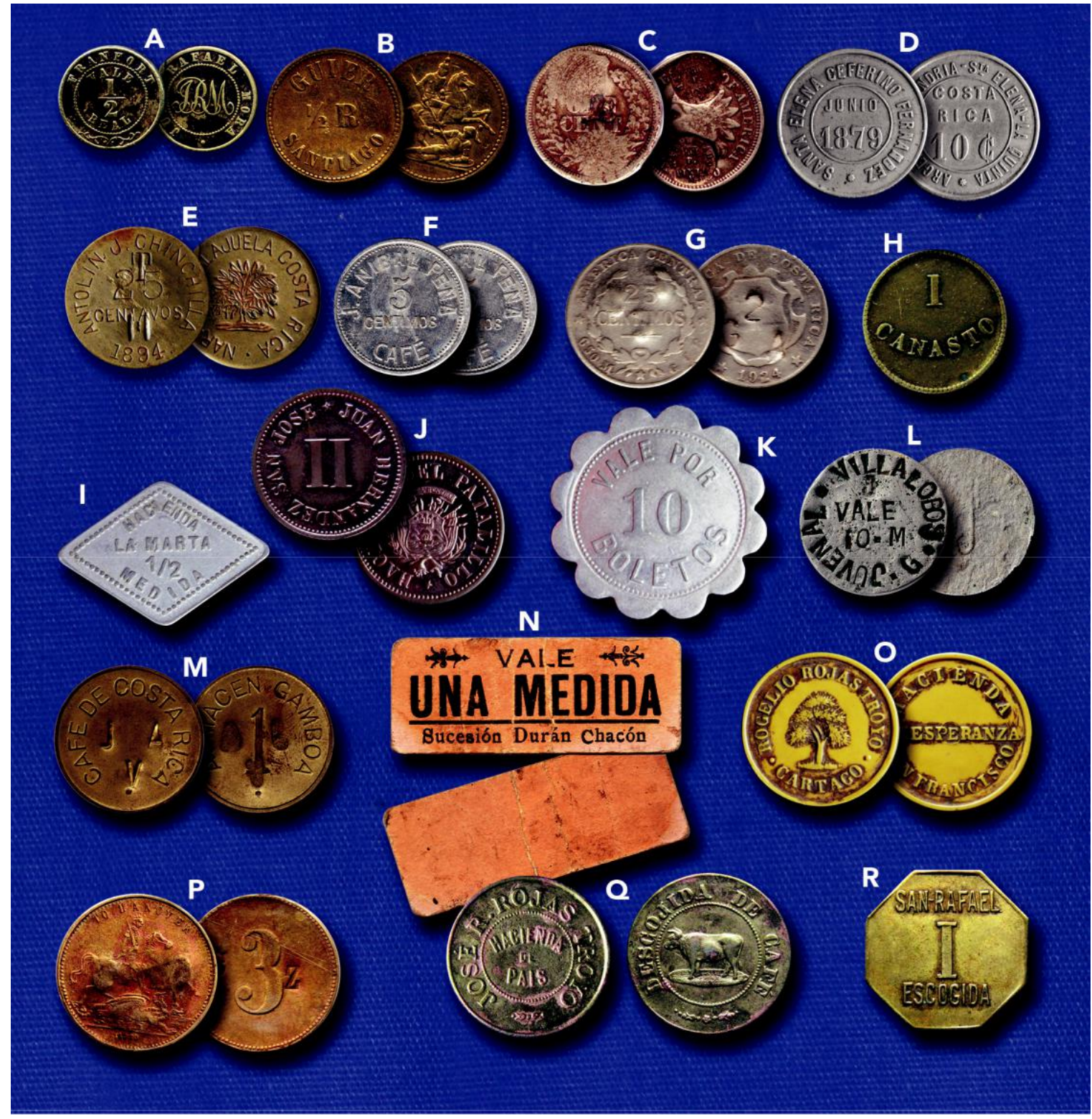

Fuente: Fotos A-R José A. Vargas Zamora. Colecciones privadas, 2019 


\section{Los boletos de café en Costa Rica: origen y tipos.}

No obstante, los esfuerzos de la Casa de Moneda para aliviar la escasez de circulante, el auge del cultivo del café y del comercio asociado a la bonanza económica que aportó a la sociedad, hizo necesario que por ahí de 1845 algunos cafetaleros adoptaran el uso de moneda privada para el pago provisional de las labores de recolección del grano en los cafetales propiedad del emisor. Esa forma de pago provisional, o boleto de café, fue acuñada generalmente en una aleación metálica (bronce o latón) cuyo valor intrínseco fuera inferior al de las monedas de plata en circulación y; por tanto, no permitiera su cambio por moneda oficial fuera de la empresa cafetalera que la emitía. Los boletos también eran fabricados con diámetros similares a los de las principales monedas en circulación.

El uso de moneda provisional debido a la escasez de circulante no fue un problema único de Costa Rica. La introducción de boletos (tokens) fue frecuente en Inglaterra desde mediados del siglo XVIII por parte de bancos, comercios, e industrias (Castro-González, 2013). A principios del siglo XIX fue introducido en Kent el uso de boletos metálicos para el pago de trabajadores agrícolas (Carson, 1962 , p. 566). Es posible que algunos macro-productores de café, que visitaron Inglaterra, observaron la utilidad de esa moneda transitoria y su potencial de uso en Costa Rica, por lo que algunos boletos posiblemente fueron acuñados en Europa a pedido de cafetaleros adinerados. El éxito de la introducción en Costa Rica de esta forma de pago, cuya legalidad no estaba clara, fue evidente. Tal como lo indican Chacón-Hidalgo y Carazo de Flores (2006, p. 17)

El uso de los boletos se impuso por dos razones: primero, la necesidad de contar con moneda de baja denominación; y segundo, por la aprobación encubierta de los gobiernos, ya que muchos personajes prominentes de la vida política del país eran cafetaleros.

El éxito de su introducción en el país en la década de 1840 favoreció, con el transcurso del tiempo y el aumento de la producción cafetalera, la aparición de boletos manufacturados de otras maneras, entre las que mencionamos:

- Boletos (tokens) en uso o desuso en Europa, importados a Costa Rica y resellados con las iniciales, el símbolo, o ambos, escogidos por el cafetalero local.

- Los habilitados mediante el resello de monedas locales o extranjeras cuyo valor era menor que el costo de fabricación o de importación de los boletos. (Ej. monedas de un centavo de Estados Unidos y de Costa Rica). 
- Los hechos con cospeles no utilizados de monedas de Costa Rica (Ej: los cospeles para centavos de cupro-níquel emitidos entre 1865 y 1874).

- Los elaborados mediante el resello de boletos de café (machotes), metálicos, importados a los que se les grababa, a pedido del cafetalero, sus iniciales u otro símbolo. Este tipo constituye una gran mayoría, especialmente los machotes traídos al país y grabados por las ferreterías Zúñiga y El Iris, así como por el Almacén Gamboa, entre otros.

- Los fabricados a mano utilizando diversos metales y grabados con punzones por el mismo cafetalero, o por un artesano local.

- Los fabricados con otros materiales como la baquelita y el plástico. Existen algunos hechos de cuero.

- Boletos de cartón, utilizados en caso de urgencia y generalmente para uso en una cosecha.

En la Figura 2 hemos incluido ejemplos de boletos que ilustran los tipos mencionados arriba.

\section{El boleto, definición y formas de uso:}

Muchos autores utilizan los términos boleto y ficha como sinónimos, no obstante que su uso fue diferente, o hubo traslape en algunos casos. Por tal motivo incluimos en este texto las definiciones de ambos.

El término boleto, según el Diccionario Enciclopédico de la Unión Tipográfica Editorial Hispano Americana (1951, Tomo II, p. 424) corresponde a:

Boleto: En Costa Rica, moneda de latón que en las plantaciones de café se da a modo de libranza a los cogedores, por cada cajuela de grano cosechado.

De igual modo ese mismo Diccionario (1951, Tomo VI, p. 1034) define libranza, así:

Libranza: Orden de pago que se da, ordinariamente, por carta, contra uno que tiene fondos a disposición del que la expide, la cual, cuando es a la orden, equivale a la letra de cambio

La restricción que hace ese Diccionario del uso del término boleto para Costa Rica es un reflejo de su uso intensivo con ese fin a mediados del siglo XX en el país. 
La efectividad del trato con boletos residía y reside en el reconocimiento por ambas partes (emisor y receptor) de un valor único asociado a la pieza en cuestión y a su cambio por dinero al final de un periodo convenido. Este acuerdo entre las partes puede tomar, entre otras, las siguientes formas:

1. El emisor (cafetalero) de los boletos le entrega al trabajador (recolector de café), por cada unidad de volumen medida (20 litros = 1 medida, o cajuela) de café, un boleto marcado con la unidad medida (cuartillo, media cajuela, una cajuela)

2. El emisor (cafetalero) de los boletos le entrega al trabajador (recolector de café), por cada unidad de volumen de café medida, un boleto marcado con el valor monetario de la unidad medida (reales, centavos, céntimos, colones)

3. El emisor (cafetalero) de los boletos le entrega al trabajador (recolector de café), previo retorno de los boletos correspondientes, un boleto marcado con un múltiplo equivalente a los boletos entregados $(2,5,10$ boletos)

4. El emisor (beneficiador) de los boletos le entrega al trabajador (escogedora de café), un boleto por cada unidad de volumen de café separado (escogido) en categorías de calidad.

5. En su estudio Solano-Ramírez (2016, p. 32) menciona cuatro usos de los boletos: A. Diario. B. De fin de semana. C. Exclusivo en el beneficio receptor del grano (Ej. Fig. No 5 C. Beneficio de Eloy León, San Pablo, Heredia, ¿por 50 cajuelas o $2 \frac{1}{2}$ fanegas?). D. Para organizar a los recolectores y dar permiso de iniciar la cogida en una calle (fila de cafetos). Se asume que el cogedor entrega el boleto al mandador (capataz) del cafetal una vez concluida y aprobada la labor en la calle laborada.

\section{El boleto de café, ventajas para el emisor:}

Según lo hemos mencionado, la introducción del uso de boletos en Costa Rica obedeció en un principio a la escasez de monedas de plata de bajas denominaciones para el pago de las labores en los cafetales. Una vez que esa escasez disminuyó, la utilidad práctica de los boletos se mantuvo e incrementó, pues había otras ventajas en continuar con su empleo, especialmente para el emisor. Estas ventajas variaron con el tiempo y según el poder monetario del emisor. Dos de las ventajas para grandes cafetaleros han sido resumidas por Viales-Hurtado y Barrantes-Zamora (2007, p. 30), así: 
...el uso de los boletos permitió atar la mano de obra a la finca, así como al área de influencia de ésta, y también permitió la acumulación mediante la utilización de la moneda para las exportaciones y el beneficio para los grandes cafetaleros mediante el cobro de intereses por los depósitos bancarios...

Castro-González (2013) menciona otras ventajas y Vargas-Zamora, RamírezVillalobos, Zamora-Herrera, García-Barquero y Chacón Hidalgo (2013, p. 45) resumen las siguientes:

Evitar, por seguridad, el transporte de dinero en efectivo a la plantación y su manejo en el cafetal.

Disminuir el tiempo necesario para la medida del café recolectado al concluir la jornada diaria y antes del ocaso.

Facilitar el conteo de cajuelas medidas y el control de pago posterior.

Forzar la permanencia de algunos recolectores cuando la mano de obra es escasa

Demorar el pago para generar interés sobre el capital.

Sustituir temporalmente el dinero por falta de liquidez del productor.

Esta última ventaja fue especialmente importante para los micro-productores de café, que fueron la mayoría según se puede inferir de la gran cantidad de boletos hechos a mano o sobre machotes importados. Muchos de esos pequeños productores no tenían disponible el dinero en efectivo para el pago de los recolectores y se veían forzados a recurrir a los boletos mientras obtenían del beneficiador, usualmente al final de la semana, el dinero para el pago respectivo previa entrega del grano recolectado al beneficiador.

\section{El cultivo del banano y las fichas}

El uso de piezas de metal similares a monedas, o el contramarcado de monedas con diversos fines es antiguo. En Inglaterra desde el siglo XVII se contramarcaron monedas obsoletas con leyendas. Las piezas marcadas servían de medio de propaganda para algún producto comercial, como las que promocionaban en el siglo XIX al jabón Pears. Fabricantes ambulantes de fichas (tokens) viajaban de pueblo en pueblo ofreciendo sus servicios para suplir a los comerciantes con 
piezas para uso como moneda provisional, o con otras para distribuir como propaganda de su producto (Brunk, 1989, p. 3).

En América Latina se utilizaron fichas en varias actividades. Por ejemplo, en las minas de salitre de Chile y en las plantaciones de caucho de Brazil (CastroGonzález (2013). En algunos países del Caribe el uso de fichas como pago temporal a trabajadores fue importante en otras plantaciones, como las de caña de azúcar. La práctica de pago mediante fichas a los cosechadores era frecuente en el siglo XIX en las plantaciones de algodón de Lousiana, en el sur de los Estados Unidos. Esas plantaciones utilizaron fichas metálicas en las que usualmente una cara tiene grabado el nombre de la empresa y la otra el valor (entre un centavo y un dólar) y la leyenda Good for (el valor) in merchandise (Lurvink, 2014, p. 144).

Las fichas tenían muchas ventajas a favor del emisor y pocas para el trabajador. Tal como lo ha descrito Elías-Caro \& Vidal-Ortega (2013):

...el ingreso real de los jornaleros se veía afectado por diversos factores. En primer lugar, estaba la forma de pago, a menudo no se efectuaba en moneda, sino en vales o fichas, práctica prohibida por las leyes pero vigente a través de sus comisariatos. Igualmente se endeudaba a los trabajadores en la tienda de la compañía - de manera directa o por parte del contratista - con lo cual el pago era remanentes una vez cubiertos los gastos. Este sistema ofrecía al empleador una ventaja adicional, pues retenía al trabajador, que endeudado o no, se veía impedido de abandonar libremente sus labores...

En Costa Rica la apertura del ferrocarril al puerto de Limón a fines del siglo XIX facilitó la exportación de café a mercados europeos y norteamericanos. También trajo la introducción de formas de pago provisionales conocidas como fichas de comisariato.

Las tierras planas concedidas a lo largo de la vía fueron utilizadas para el desarrollo de un nuevo cultivo, el banano (originario de Asia), con un mercado controlado por compañías norteamericanas. La llegada de este nuevo sistema de explotación de la tierra tuvo un gran impacto en la economía de Costa Rica y así se infiere de la alegoría pintada por el artista italiano Aleardo Villa y que adorna la escalinata del Teatro Nacional desde 1897. Esta alegoría fue incluida en el reverso de los billetes de cinco colones emitidos entre 1968 y 1992 (Carranza-Astúa, 2012, p. 412) y que reproducimos en la Figura 3. 
Figura 3. A. Reverso del billete de 5 colones del BCCR, emitidos entre 1968 y 1992, con la alegoría a los cultivos del café (derecha) y banano (centro) y su exportación por el puerto de Limón (izquierda). Obra del artista italiano Aleardo Villa que adorna, desde 1897, el cielo de la escalinata del Teatro Nacional de Costa Rica. B., C. Sellos de correos, 1950, con una cogedora de café y tres cortadores de racimos de banano.

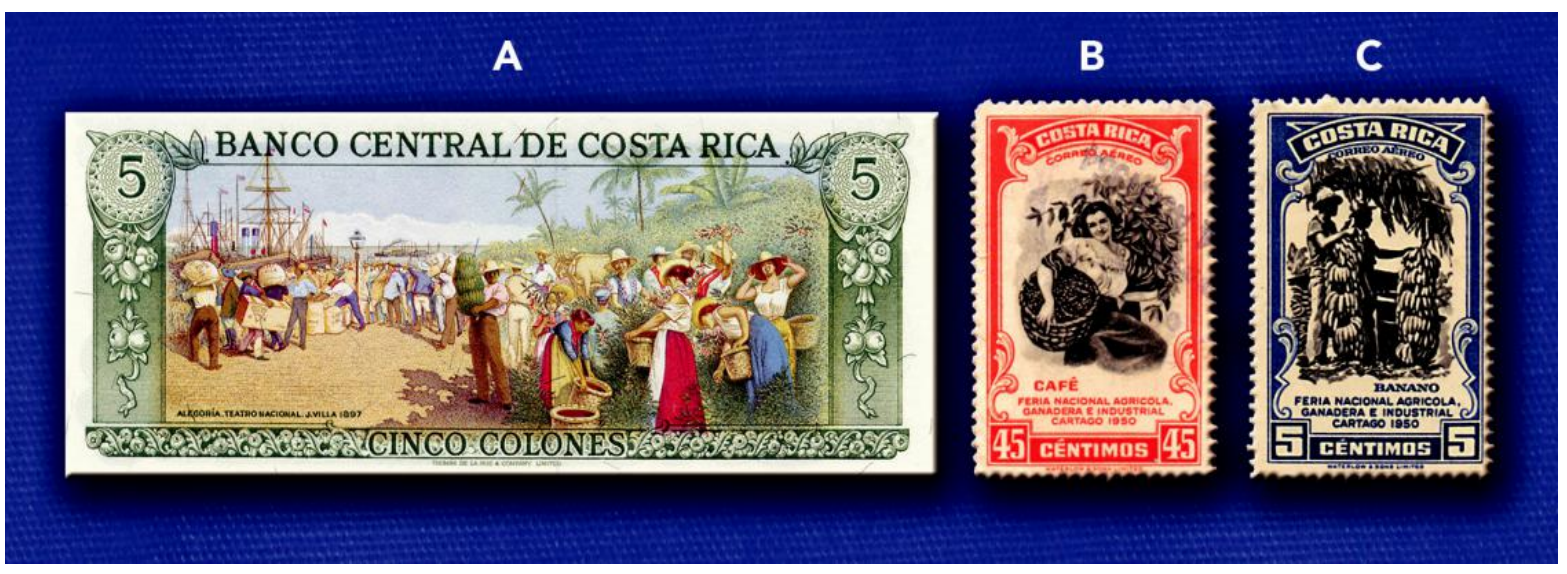

Fuente: José A. Vargas Zamora, 2019

No es sorpresa que fichas con la leyenda Good for (el valor) in merchandise fueran empleadas en Costa Rica por parte de compañías norteamericanas o afiliadas. El uso y abuso de las fichas de comisariato, a diferencia del uso de los boletos de café, fueron uno de los motivos que atizaron en Costa Rica las luchas por la justicia social en la primera mitad del siglo $X X$, por ser uno de los mecanismos más evidentes para explotar a los trabajadores ferrocarrileros y de las fincas bananeras asociadas.

Según lo indica Hernández-Rodríguez (1995, p. 83)

\begin{abstract}
...El sistema (de cupones o de ficha-salario) ampliamente difundido en la economía de plantación caribeña resultaba un instrumento de gran utilidad para recuperar el capital invertido en salarios, se trataba simplemente de reducir la circulación de dinero supliéndolo por tiquetes por el valor del trabajo realizado, que solo eran canjeables en ciertos comisariatos y expendios controlados por los productores bananeros.
\end{abstract}

La utilidad de emitir formas de pago propias era evidente, tal como lo indica Hernández-Rodríguez (1995, p. 83) con referencia a uno de los funcionarios del ferrocarril (Costa Rica Railway) quien en 1871 informa a su jefe (Minor Keith), lo siguiente: 
...estoy tratando de obtener la autorización (de parte del Gobierno) para emitir nuestro propio dinero, particularmente unidades de 50 centavos, 25 centavos y un dólar, por la buena razón que en Puerto Limón, eso sería una enorme ayuda. Nosotros pagamos a los hombres y ellos lo gastan nuevamente en el comisariato y sus sucursales: estos últimos lo devuelven a nuestras oficinas centrales, y en esa manera, lo podremos circular como debe hacerse el efectivo...

Cabe anotar que en 1872 el ferrocarril logró su objetivo y emitió billetes por valores de 10, 25 y 50 centavos, así como por 1, 2, y 5 pesos (Carranza-Astúa, 2012, p 116-121). A partir de 1891 emitió monedas de cupro-níquel con valores de 5, 10, 25 y 50 centavos, que ilustramos en la Figura 4.

Las fichas de comisariato, los billetes y las fichas del ferrocarril son tres de los varios tipos de moneda privada temporal que pueden ser agrupados bajo el término ficha. Por tal motivo, de igual modo que hicimos con el término boleto, incluimos a continuación una definición de ficha y algunos de sus usos.

En la Figura 5 incluimos varios ejemplos de fichas utilizadas en comisariatos a lo largo del ferrocarril al Caribe.

\section{Las fichas, definición y motivos para su uso}

El término ficha, según el Diccionario Enciclopédico de la Unión Tipográfica Editorial Hispano Americana (1951, Tomo V, p. 16), corresponde a:

Ficha: Pieza pequeña de cartón, metal, u otra sustancia, a la que se asigna un valor convenido y que se usa en sustitución de la moneda en algunas casas de negocios y establecimientos industriales.

Con base en lo anterior podemos mencionar cuatro usos frecuentes en Costa Rica: La mayoría de las fichas actuales son emitidas por empresas de juegos de azar.

1. El emisor (empresario) le entrega al trabajador, como pago por su labor, una ficha que podrá cambiar por productos en el establecimiento comercial (comisariato) de la misma empresa, o afiliado.

2. El emisor (empresario) le entrega al usuario una ficha que este le ha comprado para ser utilizada como pago por un servicio brindado por la empresa (transporte, teléfono público de mesa, estacionamiento de vehículo, juego de azar, etc). 
3. El emisor (empresario) emite fichas que los usuarios utilizan temporalmente dentro de la empresa como forma de asignación de turno, o de cupo.

4. El emisor (empresario) le entrega gratis al usuario una ficha como reconocimiento por compras hechas en la empresa. La ficha podrá ser canjeada por un artículo cuyo valor está predeterminado por el emisor.

La emisión de algún reconocimiento por las compras, y que sirve de incentivo para volver a la empresa, sobrevive en algunos casos bajo la forma de pequeños papelitos adheribles (stickers) que se pegan en una libreta canjeable por un producto determinado.

En la Figura 6 hemos incluido ejemplos de varios tipos de fichas utilizadas en Costa Rica por establecimientos comerciales e instituciones gubernamentales

\section{Boletos y fichas: identificación de fechas y emisores}

Los boletos y fichas con la fecha de emisión grabada son escasos. La determinación de la posible época o fecha en que fueron emitidas o utilizadas deben ser indagadas con ayuda de otros datos, como los periodos de operación de las empresas cafetaleras y comerciales, las referencias genealógicas de los emisores, a veces dispersas en periódicos, libros y bases de datos, así como en planos de fincas, mortuales, litigios y otros documentos depositados en el Archivo Nacional. Ejemplo de estas indagaciones es el estudio de SolanoRamírez (2016). En este contexto incluyo aquí un ejemplo: El escritor Manuel González Zeledón (Magón, 1864-1936) en su cuento Un baño en la presa (González-Zeledón, 1947, p. 5) menciona que un día de su infancia y de camino a la escuela, se detuvo a pedir, ...en La Esperanza de don José Trinidad Chaves, un pedacito de hielo... El cuento lo ubica Magón en el mes de marzo de 1874, por lo que la ficha de La Esperanza de J. T. Chaves (Figura 6) podría provenir de esa década y el valor $10 \mathrm{C}^{\mathrm{s}}$ grabado equivaldría a diez centavos. Si como alternativa el valor $10 \mathrm{C}^{\mathrm{s}}$ corresponde a 10 céntimos, esto indicaría que la emisión de la ficha fue después de 1896, cuando el peso de cien centavos fue sustituido por el colón de 100 céntimos. La información de Magón confirma la existencia de La Esperanza ya en 1874, pero ignoramos el año de emisión de sus fichas. 
Figura 4. Fichas (1891-1896 ?) del Ferrocarril de Costa Rica (The Costa Rica Railway Company, Limited). Minor Keith, cupro-níquel: A. 5 centavos. B. 10 centavos. C. 25 centavos. D. 50 centavos. E. Mapa de las vías del ferrocarril al Caribe (Northern Railway Company. San José Limón, 1934), ramales a fincas bananeras y estaciones principales (Modificado de Bergan \& Zen, 1934). El servicio diario salía de ambas terminales poco después de las 06:00 y llegaba a Limón a las 16:45 y a San José a las 15:40, con paradas en varias estaciones.

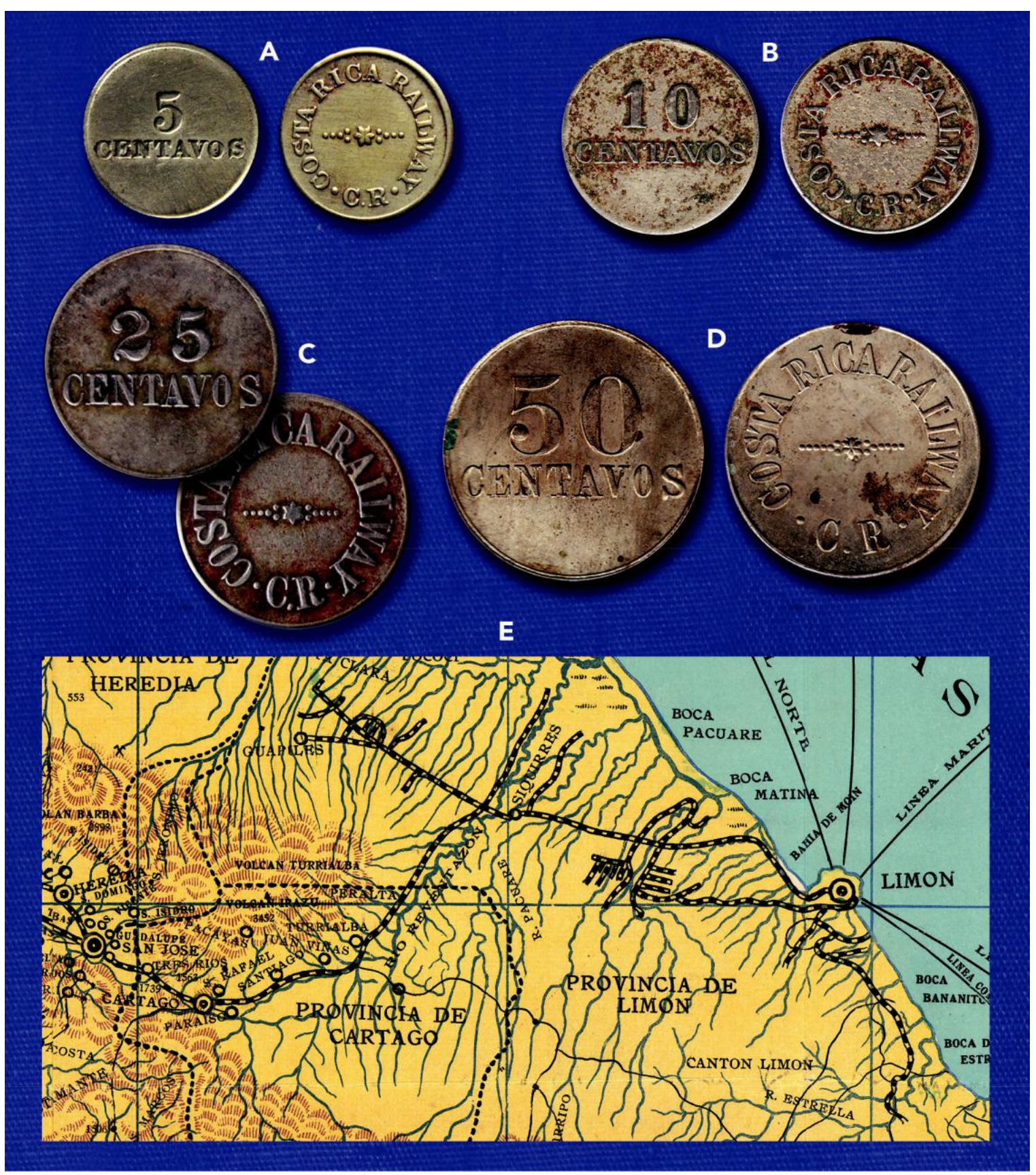

Fuente: José A. Vargas Zamora, 2019 
Figura 5. Fichas de comisariatos en la zona de influencia del ferrocarril al Caribe: A. La Roxana, Un colón, 25 y 50 céntimos. B. El Molino, 50 céntimos. Cartago. C. W. M. P.A.A.P. Vale por 50 céntimos en mercadería. Limón. Contramarcados ELV para uso como boletos de café por Eloy León Villalobos. Heredia. D, E, F. Lorig \& Tibaut. 5, 10, y 25 céntimos. Baquelita. Germania, Limón. G. Lindo \& Company. Vale por (borrado) en mercadería (Good for? in merchandise). Juan Viñas, Cartago. H. Lindo Brothers (Bros). Vale por 50 céntimos en mercadería (Good for 50 cents in merchandise). I. La Esmeralda, J. D. Peet, Juan Viñas, Vale por 25 céntimos en comercio (Good for 25 cents in trade). J. Ramón Aguilar Bolandi, 25 céntimos. Turrialba. K. Figuls \& Co. Estrada. Limón. Un colón.

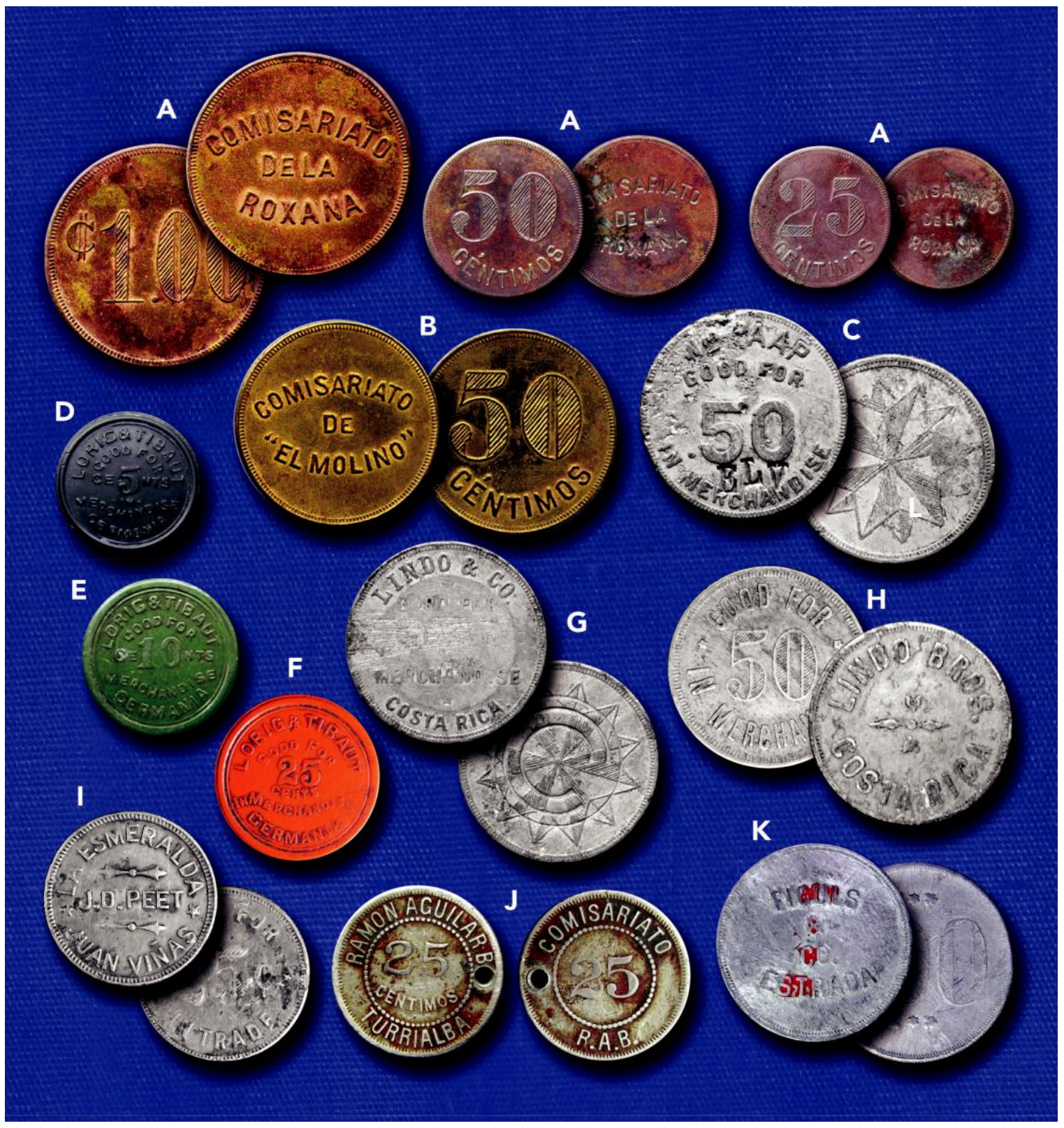

Fuente: Fotos A-K José A. Vargas Zamora. Colecciones privadas, 2019 
Figura 6. Fichas de empresas e instituciones del siglo XX. A. Ramón M. Castella. Vale por 25 céntimos en mercancía. San José. B. Costa Rica Mint. Vale por 25 céntimos en mercancía. San José. C. J. T. Chaves. La Esperanza. Pagaré 5 céntimos al portador en artículos de La Esperanza. San José. Contramarcado B (?) para uso como boleto. D. Manuel Barrios Guerra. Hacienda ganadera Santa Rosa. Vale 5 céntimos. 1904. Guanacaste. E. Federico Apéstegui. Ingenio La Mansión. Vale por 10 céntimos en mercaderías. Guanacaste (Colección Carlos A. Ramírez Villalobos, Caliche 2019). F. Pulpería La Granja, Abarrotes y Licores. Juan Ma. Vázquez. Vale por 5 céntimos. Cartón. G. Banco de Costa Rica. Ficha para espera de turno 68. San José. H. Un pasaje de bus. Ruta Tibás - San Pedro - Paso Ancho - Zapote. Plástico. I. Municipalidad de San José. Pago de estacionamiento en calle (parquímetro). 1/2 hora. J. Municipalidad de Cartago. Pago de estacionamiento en calle (parquímetro). Única pieza bimetálica de Costa Rica. K. Parque Nacional de Diversiones. Ficha para juegos. San José. L. Asociación Pro Hospital Nacional de Niños. Ficha para teléfono de mesa. San José. M. Cruz Roja Costarricense. Ficha (token) para teléfono de mesa. 20 colones. 1986.

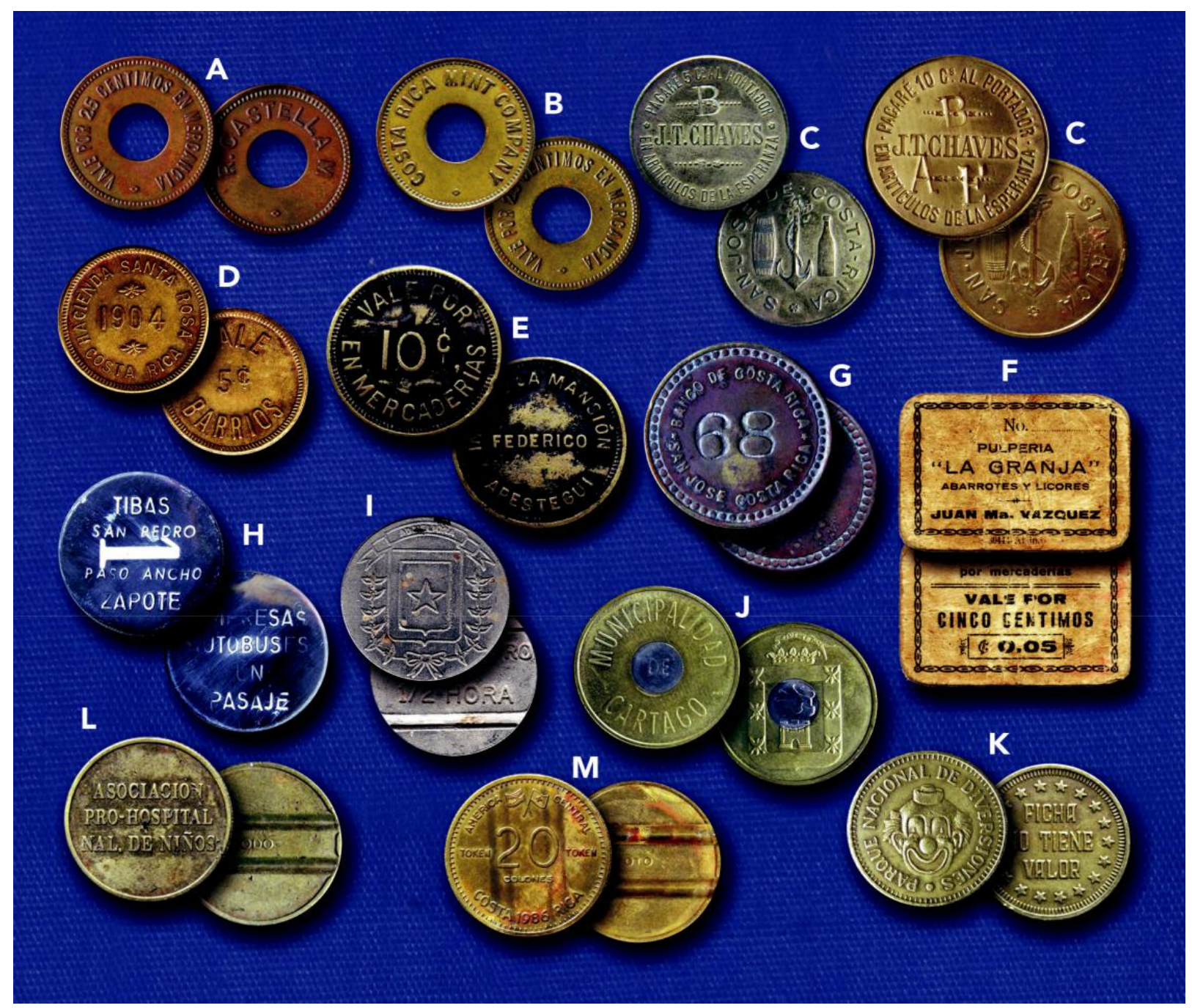

Fuente: Fotos A-M José A. Vargas Zamora. Colecciones privadas, 2019 
De una cantidad importante de boletos y fichas, el nombre de su emisor permanece incógnito. Muchos boletos tienen grabadas solo las iniciales del propietario de la empresa cafetalera y generalmente no se conocen registros oficiales de quienes los emitieron. En algunos casos esos datos están en documentos privados, o en la memoria de personas de edad avanzada por lo que la posibilidad de identificar a los cafetaleros disminuye con el tiempo. Existe información valiosa dispersa en ciertas obras, como el Anuario de Costa Rica (Bergan \& Zen, 1934) que incluye listas de exportadores, consignatarios y marcas de café, así como anuncios de productores y sus lugares de operación.

En el caso de las fichas su identificación es a veces más fácil, pues su objetivo hizo necesario que una gran parte incluyera leyendas grabadas con información sobre su emisor, aunque la mayoría no incluye la fecha de emisión.

\section{Boletos y fichas: legalidad}

Si consideramos que los primeros boletos fueron emitidos posiblemente en la década de 1840, el uso de este medio de pago estuvo vigente sin restricción legal por más de un siglo. Una situación similar se dio con las fichas.

La llegada en 1940 de las reformas sociales promovidas por el presidente Dr. Rafael Ángel Calderón Guardia y especialmente la entrada en vigor del Código de Trabajo, ordenó el uso y trató de acabar con el abuso de los boletos y fichas como medios de pago, o cambiados por mercancías. La Ley No 2, del 27 de agosto de 1943 (Artículo 165), indica que los salarios deben ser pagados en moneda de curso legal y se prohibió el pago con vales, boletos, fichas, cupones, mercaderías, o cualquier otra forma con que se pretenda sustituir la moneda circulante. El artículo anterior y su reforma (Ley 31) del 24 de noviembre de 1943 (Vincenzi, 1980: p. 58) facilitó en las fincas cafetaleras el uso de boletos, siempre y cuando su cambio por dinero se hiciera dentro de una semana a partir de su entrega. Esa práctica continúa el día de hoy en muchas plantaciones de café.

\section{Boletos y fichas: literatura}

No obstante, la importancia del uso de los boletos en la producción cafetalera de Costa Rica la mención de este medio de pago ha sido generalmente omitida por autores que han tratado el tema cafetalero. A mediados del siglo XIX, entre 
1844 y 1859, varios viajeros extranjeros (R. Dunlop, W. Marr, E. Squier, F. Meagher, y A. Trollope), cuyos relatos han sido traducidos por FernándezGuardia (2002), visitaron y describieron grandes cafetales, pero no mencionaron los boletos, que se supone eran utilizados por los grandes productores que les sirvieron de anfitriones. González-Flores (1934) en su Historia del café en Costa Rica no menciona el uso de boletos, no obstante que su hermano, don Alfredo, quien fue presidente (1914-1917) de Costa Rica, los utilizó (De bronce y con sus iniciales A.G.F.) Tampoco abordaron el tema otros autores que se han ocupado de la historia monetaria de América Central, como Young (1925), o de Costa Rica, como Soley-Guell (1975), entre otros. Chacón-Hidalgo (2003, p. 46) describe brevemente el uso de los boletos y Murillo (2004: p 134) incluye una sección sobre el tema y menciona la fabricación de punzones hechos entre 1863 y 1864 por Cruz Blanco Corrales, grabador de la Casa de Moneda. Con uno de esos punzones le habilitó a Francisco Pinto centavos norteamericanos como el ilustrado en la Fig. № 3. Entre 1865 y 1874 fueron acuñados centavos en Costa Rica y muchas de esas monedas fueron utilizadas luego como boletos mediante el grabado de las iniciales del cafetalero.

Por tanto, la disponibilidad de información publicada sobre el uso de boletos y fichas en Costa Rica es todavía escasa, especialmente la que contiene ilustraciones de las piezas. Uno de los pioneros en escribir sobre el tema fue Rojas-Solano (1972, 1979), quien hizo recopilaciones de datos y publicó fotografías de varios boletos y fichas sin hacer diferencia entre ambos tipos. Tres catálogos, impresos en los Estados Unidos, son fuentes importantes de información e imágenes: el de Schimmel (1984) basado en una de las colecciones de Rojas-Solano, el de Rulau (2002) sobre boletos (tokens) de América Latina y el de Rojas (2008), quien enfatizó los boletos de cafetaleros que utilizaron los machotes de Ferretería El Iris y del Almacén Gamboa, entre otros.

La obra más extensa sobre boletos y fichas de Costa Rica es el catálogo de Chacón-Hidalgo \& Carazo de Flores (2006), que fue precedida por un pequeño folleto (Chacón-Hidalgo \& Carazo de Flores, 2002). A estos trabajos le siguen obras basadas en el uso de boletos en zonas geográficas específicas, como Santo Domingo de Heredia (Vargas-Zamora, Ramírez-Villalobos, Zamora-Herrera, García-Barquero y Chacón-Hidalgo, 2013) y La Unión de Cartago (SolanoRamírez, 2016). Otras publicaciones están disponibles en revistas indexadas, como las de Vargas-Zamora y Gómez-Laurito (2005) sobre plantas grabadas en boletos y Castro-González (2013) sobre boletos en general. Recientemente, 
Carranza-Astúa $(2015,2016,2018,2019)$ ha hecho accesible información sobre grandes fincas que utilizaron boletos y sobre el Almacén Gamboa.

\section{Boletos y fichas: colecciones}

Tal como lo ha apuntado Castro-González (2013) los boletos y fichas forman parte de la historia de la humanidad y de Costa Rica en particular. Su importancia en la economía de Costa Rica fue relevante y lo es aun hoy, aunque en forma más modesta. Los boletos y fichas constituyen una herencia cultural valiosa y son piezas coleccionables, con un valor monetario variable asociado a sus calidades particulares (rareza, estado de conservación, emisor, tipo de grabado, material de fabricación). El interés en estas piezas trasciende el ámbito nacional, pues son objeto de estudio de la ciencia numismática, que en sentido estricto se ocupa además de las monedas, medallas y billetes bancarios. También los documentos comerciales como cheques, vales, letras de cambio, lotería antigua y acciones de empresas son apreciados por los coleccionistas (Vargas-Zamora, 2013).

A la fecha no existe para Costa Rica un inventario completo de boletos y fichas por lo que su número aproximado es objeto de especulación. Algunos coleccionistas (boleteros) estiman que el total puede estar entre 3000 y 5000 piezas. Esa amplia variedad permite al coleccionista especializarse en algún tipo de boleto o ficha. Además, su precio relativamente modesto los hace atractivos, pues son escasos los ejemplares que hoy alcanzan o superan los 500 dólares en el mercado internacional, mientras que algunas monedas y billetes de Costa Rica se cotizan en varios miles de dólares.

En todo caso, el coleccionismo de boletos y fichas es un pasatiempo que contribuye al rescate y a la conservación de esta herencia costarricense.

\section{BIBLIOGRAFIA}

Araya-Pochet, C. (1973). La minería y sus relaciones con la acumulación de capital y la clase dirigente de Costa Rica, 1821-1841. Anuario de Estudios Sociales Centroamericanos, 2, (5), 31-64.

Bergan, L., \& Zen, A. (Eds). (1934). Anuario de Costa Rica 1934. San José. Imprenta Borrasé Hnos. 722 p. 
Brunk, G. C. (1989). Merchant Countermarks on World Coins. IL Rockford. World Exonumia Press.. 157 p.

Carranza-Astúa, J. A. (2012). Historia de los billetes de Costa Rica, 1858-2012. San José. J. Carranza Astúa. 497 p.

Carranza-Astúa, J. A. (2015). Recopilación histórica; Propietarios, fincas y boletos de café en Costa Rica. San José. J. A. Carranza Astúa. 71 p.

Carranza-Astúa, J. A. (2016). Finca 1405, Las Pavas. J. A. Carrranza Astúa. 38 p.

Carranza-Astúa, J. A. (2018). Hacienda Patalillo. Historia de los señores Juan Fernández y Teodosio Castro. San José. J. A. Carranza Astúa. 38 p.

Carranza-Astúa, J. A. (2019). Historia del Almacén Gamboa. San José. J. A. Carranza Astúa. 36 p.

Carson, R. A. G. (1962). Coins of the World. NY. New York. Harper \& Brothers. $706 \mathrm{p}$.

Castro-González, J. M. (2013) Los boletos de café. Espiga, 25, 133-143.

Chacón-Hidalgo, M. B. (2003). Monedas de Costa Rica; Reseña Histórica. San José. Editorial de la Universidad de Costa Rica. 87 p.

Chacón-Hidalgo, M. B. (2008). El cacao como moneda oficial en la Costa Rica del siglo XVIII. NVMISMA, 252, 137-147.

Chacón-Hidalgo, M. B. \& Carazo de Flores, E. (2002). Los boletos de café en Costa Rica. Folleto Técnico. San José. Fundación Museos del Banco Central de Costa Rica. 20 p.

Chacón-Hidalgo, M. B. \& Carazo de Flores, E. (2006). Boletos de café de Costa Rica. San José. Fundación Museos del Banco Central de Costa Rica. 421 p.

Elías-Caro, J. E. \& Vidal-Ortega, A. (2013). Multinacionales bananeras e imperio económico en el Gran Caribe: 1900-1940. Revista Escuela de Historia Universidad Nacional de Salta, 12, (2): 1 - 25. 
Fernández, L. (1889). Historia de Costa Rica durante la dominación española 1509-1821. Madrid. España. Tipografía de Manuel Ginés Hernández. 671 p

Fernández-Guardia, R. (2002). Costa Rica en el siglo XIX: Antología de Viajeros. San José. Editorial de la Universidad Estatal a Distancia. 495 p.

González-Flores, L. F. (1934). Historia del café en Costa Rica. In: Pp. 475-508. Bergan, L., \& Zen, A (Eds). Anuario de Costa Rica 1934. San José. Imprenta Borrasé Hnos.

González-Zeledón, M. (1947). Cuentos. Edición, estudio crítico y glosario de José M. Arce. Universidad de Costa Rica. Editorial Universitaria. Sección Literatura y Arte No. 1. San José. Imprenta Nacional. 331 p.

Gudmundson, L. (1993). Costa Rica antes del café: Sociedad y economía en vísperas del boom exportador. San José. Editorial Costa Rica. 256 p.

Hernández-Rodríguez, C. (1995). Del espontaneísmo a la acción concertada: Los trabajadores bananeros de Costa Rica 1900-1955. Revista de Historia, 31, 69 125.

León-Sáenz, J. (1997). Evolución del comercio exterior y del transporte marítimo de Costa Rica 1821-1900. Colección Historia de Costa Rica. Vol. 7. San José. Editorial de la Universidad de Costa Rica. 380 p.

Lurvink, K. (2014). Strapped for cash: Non-cash payments on Louisiana cotton plantations, 1865-1908. Tijdschrift voor Sociale en Economische Geschiedenis, $11,(3), 123-151$

Mellis, E. (1891). Informe sobre las minas del Aguacate y de Los Castros. Traducido del inglés por M. Carazo y anotado por F. M. Iglesias. Extracto de los Anales del Instituto Físico- Geográfico Nacional de Costa Rica. Tomo II. 1889. San José. Tipografía Nacional. 20 p.

Murillo, J. (2004). Historia de las monedas de Costa Rica; Catálogo Numismático. San José. Editorial de la Universidad Estatal a Distancia. 236 p.

Rojas, E. (2008). Café de Costa Rica: Tokens. USA. Xlibris Corporation. 92 p. 
Rojas-Solano, H. (1972). El café en Costa Rica: Origen, Desarrollo, Leyendas. $2^{\text {da }}$ edición. San José. Oficina del Café de Costa Rica. 49 p.

Rojas-Solano, H. (1979). Los boletos y su función social y económica. San José. Oficina del Café de Costa Rica. 48 p.

Rulau, R. (2002). Latin American Tokens. 2da. Ed.. WI. Iola. Krause Publications. $479 \mathrm{p}$.

Schimmel, J. F. (1984). Costa Rica Tokens. Worldwide Tokens Series. CA. San Francisco. J. F. Schimmel. 30 p.

Solano-Ramírez, J. C. (2016). Boletos de café de Costa Rica: Región de La Unión de Cartago. Catálogo ilustrado de 267 boletos. San José. Fundación Museos del Banco Central de Costa Rica. 179 p.

Soley-Guell, T. (1975). Compendio de historia económica y hacendaria de Costa Rica. $2^{\text {da }}$ edición. Biblioteca Patria No. 12. San José. Editorial Costa Rica. 140 p.

Vargas Zamora, J. A. (2013). Rescatemos una herencia: Notafilia costarricense. Revista Herencia, 26 (1-2): 7 - 24.

Vargas Zamora, J. A. \& Gómez-Laurito, J. (2005). Algunas plantas en billetes, boletos de café y cafetales de Costa Rica (1836-2004). Lankesteriana, 5 (2): 141 158.

Vargas Zamora, J. A., Ramírez Villalobos, C. A., Zamora Herrera, F., García Barquero, D., \& Chacón Hidalgo, M. B. (2013). Cajuelas. Catálogo de 221 boletos de 140 cafetaleros de Santo Domingo de Heredia. San José, Fundación Museos del Banco Central de Costa Rica - Master Litho. 176 p.

Vargas Zamora, J. A., Chacón-Hidalgo, M.B. y Sánchez-Chaves, J. I. (2018). Las pesetas españolas reselladas en Costa Rica (1845). Fundación Museos del Banco Central de Costa Rica. Impresiones Unicornio. San José. 64 p.

Vega-Jiménez, P. (1991). De la banca al sofá: La diversificación de los patrones de consumo en San José (1857-1861). Revista de Historia, 24: 56 - 87. 
Viales-Hurtado, R. \& Barrantes-Zamora, E (2007). Mercado laboral y mecanismos de control de mano de obra en la caficultura centroamericana, Guatemala y Costa Rica en el periodo 1850-1930. Revista de Historia, 55-56, 15 - 36.

Vincenzi, A. (1980) Código de Trabajo de Costa Rica. San José, Lehmann editores. $180 \mathrm{p}$.

Young, J. P. (1925). Central American Currency and Finance. NJ. Princeton. Princeton University Press. 258 p. 
Revista Herencia, Vol. 33 (1), enero-junio, 2020. 